\title{
ATITUDES SOCIAIS EM RELAÇÃO À INCLUSÃO DE ALUNOS (AS) COM DEFICIÊNCIA NA EDUCAÇÃO SUPERIOR
}

\author{
SOCIAL ATTITUDES TOWARDS THE INCLUSION OF STUDENTS WITH \\ DISABILITIES IN HIGHER EDUCATION
}

Thelma Helena Costa Chahini ${ }^{1}$

\begin{abstract}
Resumo
Analisaram-se as atitudes de professores e alunos da Universidade Federal do Maranhão em relação à inclusão de alunos com deficiência na Educação Superior. Os participantes foram 15 alunos com deficiência; 100 alunos sem colegas com deficiência em sala de aula; 100 colegas de alunos com deficiência; 42 professores de alunos com deficiência; 100 professores sem alunos com deficiência em sala de aula. Os dados foram coletados por meio da Escala Likert de Atitudes Sociais em relação à Inclusão. Os resultados demonstram que a experiência de estudar com colegas com deficiência na mesma classe promoveu mudança nas atitudes sociais em relação à inclusão, tornando-as mais favoráveis. Os professores aceitam a inclusão dos alunos com deficiência na Educação Superior, no aspecto ideológico, mas quanto à operacionalização das práticas pedagógicas visando garantir a permanência com êxito desses alunos na instituição, suas atitudes já não são tão favoráveis.
\end{abstract}

Palavras-chave: Educação superior. Atitude social. Inclusão.

\begin{abstract}
Analysis of professors' and students' attitudes in the Federal University of Maranhão towards the inclusion of students with disabilities in higher education. The subjects are 15 students with disabilities; 100 students without peers with disability in the classroom; 100 students' peers with disability; 42 professors of students with disability; 100 professors without students with disability in the classroom. The data have been collected by means of Likert scale of social attitude toward inclusion (ELASI). The results show that studying with peers with disability in the same classroom promoted change in the social attitudes towards inclusion, making them more favorable. The professors accept the inclusion of disabled students in higher education, , in the ideological aspect, however as to the operationalization of learning practices aiming to guarantee these students to remain in the institution, their attitudes are not that favorable.
\end{abstract}

Keywords: Higher education. Social attitude. Inclusion.

\footnotetext{
${ }^{1}$ Possui o Mestrado em Educação (UFMA), Doutorado em Educação (UNESP/Marília)e Posdoutoramento em Educação Especial (UFSCar/SP). Professora Adjunta das disciplinas de Educação Especial e Psicologia da Educação no Centro de Ciências Sociais da UFMA. E-mail: thelmachahini@ hotmail.com
} 


\section{INTRODUÇÃO}

O desconhecimento da sociedade e principalmente dos educadores sobre os alunos com deficiência é um dos pontos cruciais que tende a gerar expectativas, conflitos e concepções expressivamente distorcidas em relação à avaliação da construção e do uso do conhecimento que esse aluno especial faz, dentre tantos outros equivocados conceitos, acerca desse segmento social.

Diante da dialética exclusão/inclusão no atual contexto nacional e internacional, em que a Legislação Federal vigente favorece reflexões e críticas a respeito das pessoas com deficiência que se encontram excluídas do exercício dos direitos à educação superior e, consequentemente, ao mercado de trabalho, desenvolveu-se este estudo com o objetivo de analisar as atitudes sociais de professores e alunos da Universidade Federal do Maranhão em relação à inclusão de alunos com deficiência na Educação Superior.

Considerando-se que atos jurídicos devem ser acatados e, portanto, postos em prática, não há como negar o processo de inclusão. Ele existe, de fato, pela via legal. Isso, no entanto, não é suficiente para determinar a permanência com êxito e a conclusão de seus cursos, àqueles que são incluídos.

É notória a questão das dificuldades existentes em relação à prática de aceitação e da inclusão de pessoas com deficiência em todos os setores sociais. No caso do ensino, a formação fragmentada do profissional de educação acarreta, como consequência, um grau de despreparo do professor o que, de certo modo, dificulta a operacionalização do discurso sobre a inclusão de pessoas com deficiência e/ou com necessidades educacionais específicas em todos os níveis de ensino.

\section{AS ATITUDES SOCIAS E O PROCESSO DE INCLUSÂO}

As atitudes sociais são predisposições a comportamentos em determinadas situações, derivadas de valores internalizados durante o processo de desenvolvimento de cada pessoa. Não observadas diretamente, mas sim inferidas. Representam nossos gostos e desgostos, nossas afinidades e aversões por determinadas situações. Desempenham funções específicas para cada pessoa, servindo como ajuda à formação de ideias mais estáveis da realidade e servem de base para situações sociais importantes (RODRIGUES, 1973). Para Rodrigues (2009) atitude social é uma organização duradoura de crenças e cognições em geral, dotada de 
Atitudes sociais em relação à inclusão de alunos (as) com deficiência...

carga afetiva pró ou contra um objeto social definido, que dispõe a uma ação coerente com as cognições e afetos relativos a esse objeto.

Ainda segundo o autor, se não gostamos de pessoas pertencentes a um determinado grupo, necessariamente temos uma série de pensamentos relativos a tal grupo e, ao encontrarmos um membro desse grupo, manifestamos, por meio de ações específicas, que com ele não simpatizamos. Os elementos (afeto, cognição e comportamento) influenciam-se mutuamente, pois, há uma tendência a fazer com que esses elementos sejam coerentes, isto é, se somos contra algo, temos cognição acerca desse algo que justifica ou explica nosso sentimento negativo e, em conseqüência, tendemos a nos comportar de forma hostil em relação a tal objeto.

Durante as relações interpessoais surgem manifestações de vários fenômenos psicológicos como os afetos e desafetos, dentre os quais, as formações de atitudes, estereótipos, preconceitos, cooperação, competição etc. (RODRIGUES, 2007). Ainda em relação ao assunto, as pessoas com preconceitos contra determinados grupos só veem neles manifestações que se coadunam com sua visão preconceituosa e passam por cima de tudo o que contradiz tal visão. (RODRIGUES; ASSMAR; JABLONSKI; 2009).

A esse respeito, Buscaglia (2006) pontua que os sentimentos da maioria das pessoas pelos indivíduos com deficiência afloram expectativas preconcebidas em relação ao comportamento do deficiente. $\mathrm{O}$ autor afirma que essas atitudes podem imputar limitações nos potenciais destas mesmo quando a deficiência não o fizer, visto que a natureza pessoal das percepções tende a ver o que as pessoas querem ver, a ouvir o que desejam ouvir. Ainda de acordo com o autor, é possível que nossa percepção pouco ou nada tenha a ver com a realidade da pessoa deficiente diante de nós.

Tanto a pessoa que nasce com deficiência, quanto a que a adquire posteriormente, serão menos limitadas pela própria deficiência do que pela atitude da sociedade em relação a ela, pois é a sociedade que na maioria das vezes define a deficiência como algo incapacitante e as pessoas com deficiência sofrem as consequências dessa definição (BUSCAGLIA, 2006). Para o referido autor é a sociedade quem cria os incapazes.

Nesse sentido, Sade e Chacon (2008) relembram que as barreiras atitudinais tanto no passado quanto no presente, impediram e ainda impedem as pessoas com deficiência de exercer seus direitos de cidadãos na sociedade.

Acredita-se, assim como Omote (1990, p. 168), que se faz necessário estudar as suposições e crenças das pessoas que reconhecem outras como deficientes e, por isso, tratamInterfaces da Educ., Paranaíba, v.7, n.19, p.314-328, 2016. 
nas de modo distintivo, pois "o processo de julgamento e interpretação que as pessoas comuns fazem das deficiências e das características dos deficientes deve ser incluído no estudo das deficiências como parte integrante e crucial do fenômeno". Neste cenário, o autor esclarece que os usuários desses conhecimentos podem não estar suficientemente conscientes das inúmeras e complexas influências que suas percepções em relação às deficiências sofrem em função de suas histórias passadas, dos seus modos de inserção na sociedade e das relações com as pessoas com deficiência.

Frente a essas circunstâncias, Oliveira (2006) enfatiza que uma das dificuldades para a inclusão de alunos com necessidades educacionais especiais nas instituições de ensino é a superação de determinados saberes, imaginários e representações sobre essas pessoas, demarcadas por visões de mundo estigmatizadas e materializadas em práticas sociais e educacionais de discriminação e de exclusão. Para a autora, as representações sociais assim como o imaginário, têm caráter coletivo e são constituídas por conceitos, imagens e percepções compartilhadas por várias pessoas e socializadas para as novas gerações através da família, das instituições de ensino e de diversos grupos sociais.

Oliveira ressalta ainda que para se compreender a questão das diferenças predeterminadas pela sociedade, precisa-se analisá-las no contexto do universo simbólico dos imaginários e das representações sociais, considerando que as referidas representações se materializam em atitudes de discriminação e práticas de exclusão. De acordo com a autora, as instituições de ensino reproduzem representações sociais estigmatizadas de pessoas consideradas "diferentes", contribuindo para a exclusão de todos os que não se enquadram nos referenciais culturais preestabelecidos.

Nos estudos de Baleotti (2006), os professores da Educação Básica que tiveram a oportunidade de terem em sala de aula alunos com deficiência e/ou com necessidades educacionais especiais, demonstraram mais atitudes sociais favoráveis à inclusão do que os que ainda não tinham tido tal oportunidade.

A esse respeito, acrescentam-se os estudos de Clark (1997) e de Yuker (1988) ao verificarem que a experiência de contato com pessoas com deficiência é uma variável importante na determinação dos professores em relação ao acesso e ao aprendizado com êxito de alunos com tais necessidades nas instituições de ensino.

Tanto Clark (1997) quanto Florin (2001) afirmam que as atitudes de professores e/ou de profissionais no processo ensino-aprendizagem, podem facilitar ou restringir a 
Atitudes sociais em relação à inclusão de alunos (as) com deficiência...

implementação das políticas de inclusão, pois a eficácia dessa política depende da cooperação desses profissionais, visto que as atitudes destes causam fortes impactos nas atitudes de seus alunos.

O contato social com pessoas com deficiência, também pode produzir atitudes desfavoráveis acerca da inclusão dessas pessoas. (FORLIN, 1995).

Verifica-se nos estudos de Omote et al. (2003), sobre atitudes sociais de educadores em relação à inclusão, que apesar de os resultados serem favoráveis à inclusão, os professores demonstravam uma certa preocupação em relação à presença efetiva de alunos com necessidades educacionais especiais em sala de aula, devido entre outros, ao descuido do poder público com a provisão de recursos e condições necessárias para a construção de ensino efetivamente inclusivo; a falta de adequação tanto na edificação quanto nos mobiliários; escassez de acervo e de laboratórios, além da própria qualificação dos professores, que praticamente não é exigida.

Sobre o assunto em questão, Pinheiro (2003) verificou através de dados empíricos que os professores, ideologicamente, apresentavam atitudes favoráveis à inclusão, mas quanto à operacionalização, de fato, mostravam-se bastante contraditórios, isto é, desfavoráveis à inclusão de alunos com deficiência nas instituições de ensino.

Apesar de as atitudes sociais dos professores e alunos (futuros professores) serem favoráveis à inclusão, o mesmo não ocorre em relação à operacionalização das ideias inclusivistas (OMOTE et al., 2003). Entre a educação que existe e a educação inclusiva que se pretende ter, o professor vem linha na de frente, com sua carência de formação especializada e suas atitudes sociais à inclusão. Não raro se encontram situações em que "[...] os mestres, carentes muitas vezes de uma formação prévia explícita que lhes permita refletir sobre sua tarefa e inová-la, costumam reproduzir modelos docentes e instrucionais que eles mesmos receberam de modo implícito". (POZO, 2002, p. 196).

$\mathrm{O}$ estudo das atitudes sociais no processo ensino-aprendizagem, principalmente dos professores em relação à inclusão de alunos com deficiência na educação superior, permite que se tenha uma ideia de suas práticas pedagógicas em sala de aula, visto que o conhecimento das atitudes de uma determinada pessoa admite inferências sobre seu comportamento. (RODRIGUES, 1973).

Estudos demonstram que os professores não vêm recebendo formação especializada que propicie uma nova visão de ensino e de aprendizagem fundada em atitudes que favoreçam 
o acesso e garantam a permanência dos alunos com deficiência nas Instituições de ensino. (OMOTE et al., 2006).

É importante salientar que quando uma pessoa apresenta atitudes favoráveis em relação a uma determinada situação, estará, por consequência, disposta a ajudar, recompensar e colaborar, mas se a mesma pessoa apresentar atitudes desfavoráveis estará disposta a prejudicar, punir ou destruir (KRECK; CRUTCHFIELD; BALLACHEY, 1969). Percebe-se que as barreiras atitudinais fazem com que as pessoas com deficiência não sejam vistas como merecedoras dos mesmos direitos que têm as pessoas sem deficiência.

O indivíduo estigmatizado pode, de maneira indireta, tentar corrigir a sua condição, dedicando um grande esforço individual em dominar áreas de atividades consideradas como não adequadas às pessoas em sua condição, pois durante as relações sociais de contatos mistos (entre pessoas sem estigmas e estigmatizados), a pessoa que possui estigma não sabe como será recebido pelo outro, se estará sendo analisado e como será interpretado. (GOFFMAN, 2008).

Existem valores e representações no mundo que acabam por excluir as pessoas. Estas, portanto, não são rejeitadas apenas física, geográfica ou materialmente, mas são excluídas de todas as riquezas espirituais, em que seus valores não são reconhecidos, ou seja, a exclusão é tão abrangente que se estende à própria cultura. (WANDERLEY, 2009).

Fato esse que Omote (2003) lamenta quando se refere à educação, das pessoas que sofrem exclusão social. Alude ao benefício que estas devem ter por direito como o acesso ao patrimônio mais precioso da humanidade, os bens intelectuais e culturais, essenciais para o exercício da cidadania e para minimizar as desigualdades sociais.

Sobre essa questão Mantoan (2008) alerta para o fato de que é na sala de aula que podem ser verificadas as crises educacionais, bem como se as mudanças no ensino verdadeiramente se efetivam ou fracassam.

Neste sentido, Oliveira (2004) informa que o imaginário coletivo social e educacional da sociedade para com as pessoas com deficiência é, na maioria das vezes, o de seres diferentes e incapazes e, portanto, não aceitos, não respeitados como cidadãos, rotulados e excluídos pela sociedade. A autora esclarece que as representações discriminatórias de que esses alunos são seres diferentes das demais pessoas sem deficiência, estão presentes nas instituições de ensino, no imaginário social de professores, de alunos, inclusive em suas próprias famílias. 
Atitudes sociais em relação à inclusão de alunos (as) com deficiência...

Ao se referir sobre a formação de futuros educadores Omote (2001) ressalta que esses alunos precisam ter oportunidades que os levem a reflexões, a análises críticas de suas próprias crenças e sentimentos a respeito das pessoas com deficiência, além do envolvimento com a construção de uma nova ordem social envolvendo essas pessoas, necessários à mudança na mentalidade da sociedade como um todo e na construção de uma sociedade genuinamente inclusiva, justa e igualitária. Ainda segundo o autor, ultimamente todos os setores da sociedade estão, de alguma forma, preocupados com a questão da inclusão e da oportunidade de acesso das minorias tradicionalmente excluídas. E isso pode representar um salto qualitativo em direção ao atendimento mais cidadão aos deficientes.

Estudos como os de Pinheiro (2003), Baleotti (2006), Silva (2008), Pereira Junior (2009), desenvolvidos na Educação Básica, apontam que professores com maior formação, bem como os que tiveram ou tem experiências de sala de aula com alunos com deficiência e/ou com necessidades educacionais especiais, tendem a desenvolver atitudes sociais mais favoráveis à inclusão.

Em conformidade com as questões anteriores, Omote et al. (2005), esclarecem que embora os professores apresentem atitudes favoráveis à inclusão de alunos com deficiência nas instituições de ensino, isto, por si só, não garante a construção de uma educação inclusiva, visto que esses profissionais necessitam também de suporte de várias ordens para o desenvolvimento de atividades adequadas em sala de aula. Faz-se necessário, acima de tudo, construir uma cultura inclusiva no interior das instituições de ensino e na sociedade de forma geral.

\section{MÉTODO}

Para a operacionalização desta pesquisa solicitou-se à Pró-Reitoria de Ensino da Universidade Federal do Maranhão, autorização para a coleta de dados na referida instituição. Após o recebimento da Declaração permitindo a realização da pesquisa iniciaram-se os contatos com coordenadores de curso, professores e alunos participantes neste estudo. $\mathrm{O}$ Projeto que deu origem a este estudo foi submetido ao Comitê de Ética da UNESP e teve parecer favorável ao desenvolvimento da pesquisa.

No total, este estudo teve 357 participantes, subdivididos em cinco grupos: 
Grupo 1 (G1), formado por alunos com deficiência. Sendo 09 alunos com deficiência que ingressaram na Universidade através da Política de Cotas a partir do primeiro semestre de 2007 ao segundo semestre de 2008 (auto-declarados com deficiências: física, visual, auditiva e motora) e 06 alunos com deficiência que ingressaram antes da referida Política. Totalizando 15 alunos com deficiência.

Grupo 2 (G2), formado por 100 alunos que não tinham colega com deficiência em sala de aula. Grupo 3 (G3), formado por 100 alunos que tinham colega com deficiência em sala de aula. Grupo 4 (G4), formado por 42 professores que tinham aluno com deficiência em sala de aula. Grupo 5 (G5), formado por 100 professores que não tinham aluno com deficiência em sala de aula.

Os instrumentos utilizados compreenderam Escala Lickert de Atitudes Sociais em relação à Inclusão (ELASI) formas A e B.

A ELASI é um instrumento que foi elaborado pelo Grupo de Pesquisa "Diferença, Desvio e Estigma" da Universidade Estadual Paulista (UNESP), Campus de Marília, obedecendo a todos os critérios necessários de padronização e confiabilidade, tendo como objetivo mensurar as atitudes sociais frente à inclusão com rigor científico, evitando que as discussões acerca da realidade social da inclusão sejam apenas opinativas ou baseadas em dogmas (OMOTE, 2005).

A coleta de dados foi realizada por amostragem, dentro das normas apresentadas pela pesquisa científica, através da ELASI formas A e B. Os escores foram obtidos de acordo com cada grupo de participantes, o número de participantes, a forma da escala que respondeu, a variação indicada pelo menor escore e o maior escore, a mediana e a variação, indicada pelos valores de quartil 1 e quartil 3 para cada uma das formas da ELASI.

Após a coleta de dados os resultados obtidos foram tabulados, categorizados e organizados em tabelas demonstrativas. Foram tratados por métodos estatísticos e analisados com procedimentos quantitativos e qualitativos. $\mathrm{O}$ escore total de cada participante foi obtido pela soma das notas atribuídas aos 30 itens da ELASI formas A e B.

Ao fazer comparações entre: alunos com deficiência que ingressaram na universidade por cotas (G1a) e alunos com deficiência que ingressaram na universidade pelo concurso vestibular tradicional (G1b); Alunos sem colegas com deficiência (G2), com os colegas de alunos com deficiência (G3); Professores de alunos com deficiência (G4), com professores 
Atitudes sociais em relação à inclusão de alunos (as) com deficiência...

sem alunos com deficiência (G5), foi usado Mann-Whitney Test (SIEGEL, 1981), com objetivo de analisar se havia diferenças entre os escores de cada grupo de participantes.

\section{RESULTADOS E DISCUSSÃO}

De acordo com a literatura internacional Forlin (1995), Clark (1997), Yuker (1988), Florin (2001) que supõe que o convívio entre pessoas com deficiência pode mudar as atitudes sociais das pessoas sem deficiência, aplicou-se o instrumento ELASI nas formas A e B nos participantes deste estudo, com objetivo de analisar suas atitudes em relação à inclusão de alunos com deficiência na Universidade.

Como podia haver diferença significante entre os alunos que ingressaram na universidade pelo sistema de cotas (G1a) e os alunos com deficiência que ingressaram pelo concurso vestibular tradicional (G1b), em relação às atitudes sociais para a inclusão, visto que nem todas as pessoas com deficiência precisam de ações afirmativas para ingressar na Educação Superior fez-se a comparação entre os escores desses grupos por meio da prova de Mann-Whitney, verificando-se que a diferença não chega a ser estatisticamente significante entre os escores dos alunos cotistas e dos alunos não cotistas $(\mathrm{p}=0,1234)$. Por essa razão, na análise dos dados relativos às atitudes sociais, os estudantes com deficiência foram reunidos num único grupo (G1).

O fato de alunos e professores da Universidade Federal do Maranhão terem dentro de sala de aula pessoas com deficiência poder contribuir para mudar suas atitudes sociais, mensurou-se as atitudes sociais dos grupos G1, G2, G3, G4 e G5. A seguir verificam-se os resultados obtidos das comparações entre esses grupos.

As análises realizadas indicam que as atitudes sociais em relação à inclusão, mensuradas pela ELASI A dos alunos com deficiência (G1) não se diferenciam significativamente das atitudes dos alunos sem colegas com deficiência (G2) p=0,2305. As atitudes sociais dos alunos com deficiência (G1), mensuradas pela ELASI forma A, também não se diferenciam significativamente das dos colegas de alunos com deficiência (G3) $\mathrm{p}=0,7086$. As atitudes dos colegas de alunos com deficiência (G3), mensuradas pela ELASI forma A, são mais favoráveis que as dos estudantes que não têm colega com deficiência em sala de aula $(\mathrm{G} 2) \mathrm{p}=0,0117$. 
As atitudes sociais em relação à inclusão mensuradas pela ELASI B dos colegas de alunos com deficiência (G3) são mais favoráveis que as dos estudantes que não têm colega com deficiência $(\mathrm{G} 2) \mathrm{p}=0,0006$.

É importante destacar que apesar de se realizar duas formas diferentes de comparação (ELASI formas A e B), os resultados apontam que quem tem colegas com deficiência em sala de aula, têm atitudes sociais mais favoráveis à inclusão do que os alunos que não têm colega com deficiência em sala de aula.

Percebe-se que entre os estudantes, a experiência de estudar com colegas com deficiência na mesma classe tornam suas atitudes sociais em relação à inclusão mais favoráveis.

Em relação aos resultados obtidos com os alunos, isto deve ocorrer devido ao convívio em sala de aula como colegas de classe, significa que além do convívio cotidiano há também o desempenho dos mesmos papéis, visto que todos são estudantes. E, provavelmente, esse convívio se estende para outras situações, tanto dentro da universidade quanto fora, nas relações sociais.

Acreditando-se que o fato de os professores da Universidade Federal do Maranhão, terem em sala de aula alunos com deficiência podia influenciar suas atitudes sociais à inclusão, compararam-se suas atitudes sociais com as dos professores que não tinham alunos com deficiência em sala de aula (G5). Os dados demonstram que as atitudes sociais em relação à inclusão dos professores que têm alunos com deficiência (G4) não se diferenciam significantemente das dos professores que não têm aluno com deficiência em sala de aula (G5) $\mathrm{p}=.0,3650$, isto é, os professores que têm alunos com deficiência em sala de aula, não têm atitudes sociais em relação à inclusão mais favoráveis que os professores que não têm alunos com deficiência.

Nesse caso, a experiência entre os professores de ter em sua classe algum aluno deficiente parece não afetar suas atitudes sociais em relação à inclusão. Provavelmente porque "esse contato" com o aluno com deficiência em sala de aula, ocorre apenas ocasionalmente, isto é, algumas poucas horas durante a semana, de maneira que cada um desempenha um determinado papel muito específico, no caso, um de professor, outro de aluno. O que não ocorre entre os alunos visto que esses permanecem mais tempo em contato com os colegas com deficiência do que os professores com os referidos alunos. Talvez alguns professores sequer tenham conhecimento de que há na classe algum aluno deficiente. 
Atitudes sociais em relação à inclusão de alunos (as) com deficiência...

Vale acrescentar aqui os estudos de Bender, Scott e Vail (1995) ao ressaltarem que professores que têm atitudes desfavoráveis à inclusão, utilizam práticas pedagógicas inclusivas com pouca frequência em relação aos professores que apresentam atitudes favoráveis.

Diante da questão de que as atitudes sociais podem variar em função da idade, de acordo com os estudos apresentados por Balboni e Pedrabissi (2000), verificou-se se as idades dos participantes era uma variável que podia influenciar os escores obtidos. Cada grupo foi subdividido em mais jovens e mais velhos, em função da idade mediana. Foram comparados, para cada grupo, os escores dos mais jovens com os mais velhos. Para tanto, utilizou-se o teste de Mann-Whitney.

De acordo com os dados encontrados, entre os alunos com deficiência (G1) mais jovens e os mais velhos que responderam a ELASI forma $\mathrm{A}$, não há diferença estatística significante entre os escores dos mais jovens e dos mais velhos $(\mathrm{p}=0,8479)$. Entre os alunos sem colegas com deficiência $(\mathrm{G} 2)$ mais jovens e os mais velhos que responderam a ELASI forma $\mathrm{A}$, os dados indicam que também não existe diferença significante entre os escores destes $(p=0,2307)$. Entre os colegas de alunos com deficiência (G3) mais jovens e os mais velhos que responderam a ELASI forma $\mathrm{A}$, também não há diferença significante entre os escores $(p=0,4999)$. Entre os professores de alunos com deficiência (G4) mais jovens e os mais velhos que responderam a ELASI forma A, não há diferença significante entre os escores destes ( $p=0,3081)$. Entre os professores sem alunos com deficiência (G5) mais jovens e os mais velhos que a ELASI forma A, também não existe diferença significante entre os escores $(\mathrm{p}=0,8008)$.

Entre os alunos sem colegas com deficiência (G2) mais jovens e os mais velhos que responderam a ELASI forma $\mathrm{B}$, não apresentam diferença significante entre os escores dos mais jovens e dos mais velhos ( $\mathrm{p}=0,9158)$. Entre os colegas de alunos com deficiência (G3) mais jovens e os mais velhos que responderam a ELASI forma $\mathrm{B}$, também não apresentam diferença significante entre os escores $(\mathrm{p}=0,4171)$. Entre os professores sem alunos com deficiência (G5) mais jovens e os mais velhos que responderam a ELASI forma B, não existe diferença significante entre os escores destes $(p=0,9745)$.

Percebe-se que nas comparações entre os mais jovens e os mais velhos por grupos, os dados indicam que não há diferença significante entre os participantes da pesquisa em relação à inclusão, em função da idade. Tanto no grupo dos alunos quanto no grupo dos professores não existem diferenças de atitudes em relação à inclusão de alunos com deficiência na Interfaces da Educ., Paranaíba, v.7, n.19, p.314-328, 2016. 
Educação Superior, visto que tanto os participantes mais novos quanto os mais velhos apresentam atitudes semelhantes. Concluiu-se neste caso, que, a idade dos participantes é uma variável que não exerce influência em suas atitudes sociais.

\section{CONSIDERAÇÕES FINAIS}

O acesso dos alunos com deficiência na Educação Superior não depende diretamente do querer ou não querer do professor. Mas, uma vez inserido em uma instituição de ensino, o desempenho educacional desse aluno, bem como seu comportamento diante do processo ensino-aprendizagem, podem depender de como será recebido em sala de aula por seus colegas e professores.

As atitudes sociais dos alunos com deficiência em relação à inclusão não se diferenciaram significantemente das de alunos sem deficiência. Já entre estes, foi encontrada diferença significante entre aqueles que tinham convívio com colega com deficiência na sua sala de aula e aqueles que não tinham essa experiência. Aventou-se a possibilidade de ter ocorrido essa diferença em função de o convívio com colegas deficientes ocorrer em um contexto no qual as duas partes encontram-se do mesmo lado e desempenham os mesmos papéis, o que pode favorecer relações interpessoais mais colaborativas que competitivas, podendo inclusive esse relacionamento se estender a contextos extramuros da Universidade.

Já entre os docentes, a experiência de ter em sua classe alunos com deficiência parece não exercer efeito sobre as atitudes sociais em relação à inclusão. Possivelmente, a natureza da relação dos docentes com cada uma das classes nas quais ministra aulas e com cada um de seus alunos não permite que se detenham em relações interpessoais específicas para a compreensão e eventual equacionamento de dificuldades que algum aluno possa apresentar. Não seria absurda a possibilidade de que algum docente sequer venha a ter conhecimento de que algum de seus alunos tivesse deficiência, se esta não for imediatamente perceptível.

Com relação à idade cronológica, tanto entre estudantes quanto entre professores, o presente estudo não evidenciou haver correlação com as atitudes sociais em relação à inclusão. Os participantes mais jovens e os mais velhos mantinham atitudes sociais igualmente favoráveis (ou desfavoráveis) em relação à inclusão. 
Atitudes sociais em relação à inclusão de alunos (as) com deficiência...

Os esforços sociais e governamentais, no plano do ensino universitário, para garantir acesso e permanência a todos os estudantes, independentemente das condições anatomofisiológicas, psicossociais, socioeconômicas ou etnoculturais deles, precisam ter também a preocupação de promover ambientes sociais acolhedores na Universidade. Isto pode implicar, entre outras providências, até mesmo ações específicas que contribuam para a construção de atitudes sociais genuinamente favoráveis à inclusão em todo o corpo docente, já que a mera presença de algum aluno deficiente na classe parece não sensibilizar suficientemente os professores, comumente ocupados com alta carga horária docente e com compromissos para com a aprendizagem de numerosos alunos.

Sabe-se que o processo de inclusão não depende somente de atitudes favoráveis, visto que existem várias implicações e dificuldades de ordens operacionais que impedem a operacionalização dos princípios da inclusão, mas sabe-se também que muitas dessas implicações e dificuldades derivam de atitudes desfavoráveis por parte de pessoas que poderiam favorecer a concretização de tais princípios.

\section{REFERÊNCIAS}

BALBONI, Giulia; PEDRABISSI, Luigi. Attitudes of italian teachers and parents toward school inclusion of students with mental retardation: the role of experience. Education and Training in Mental Retardation Developmental Disabilities, Reston, v. 35, n. 2, p. 148-159, 2000. Disponível em: <http://vnweb.hwwilsonweb.com/hww/results/results_single_fulltext.jhtml;hwwilsonid=FVA ODLBCXAZE3QA3DIMSFF4ADUNGIIV0>. Acesso em: 5 abr. 2010.

BALEOTTI, Luciana Ramos. Um estudo do ambiente educacional inclusivo: descrição das atitudes sociais em relação à inclusão e das relações interpessoais. 2006. $183 \mathrm{f}$. Tese (Doutorado em Educação) - Faculdade de Filosofia e Ciências, Universidade Estadual Paulista, Marília, 2006.

BENDER, Willian N.; SCOTT, K.; VAIL, C. D. Teachers' attitudes toward increased mainstreaming: implementing effective instruction for students with learning desabilities. Journal of Learning Disabilities, Chicago, v. 28, n. 2, p. 87-94, 1995.

BUSCAGLIA, Leo F. Os deficientes e seus pais: um desafio ao aconselhamento. Rio de Janeiro, RJ Record, 2006.

CLARK, M. Teacher response to learning disability: a test of attributional principles. Journal of Learning Disabilities, Chicago, v. 30, n. 1, p. 69-79, 1997.

FLORIN, C. Inclusion: identifying potential stressor for regular class teachers. Educational Research, Slough, v. 43, n. 3, p. 35-45, 2001. 
FORLIN, C. Educators" beliefs about inclusive practices in Western Australia. British Journal of Special Education, Hoboken, v. 22, n. 4, p. 179-185, 1995.

GOFFMAN, Erving. Estigma: notas sobre a manipulação da identidade deteriorada. Rio de Janeiro, RJ: LTC, 2008.

KRECK, David; CRUTCHFIELD, Richard S.; BALLACHEY, Egerton L. O indivíduo na sociedade: um manual de psicologia social. São Paulo, SP: Pioneira: USP, 1969. v. 1.

MANTOAN, Maria Tereza Eglér (Org.). O desafio das diferenças nas escolas. Petrópolis, RJ: Vozes, 2008.

OLIVEIRA, Ivanilde Apoluceno de. Saberes, imaginários e representações na educação especial: a problemática ética da "diferença" e da exclusão social. Petrópolis, RJ: Vozes, 2004.

Saberes, imaginários e representações sobre pessoas que apresentam necessidades especiais no cotidiano escolar. In: MARTINS, Lúcia de Araújo Ramos et al. (Orgs.). Inclusão: compartilhando saberes. Petrópolis, RJ: Vozes, 2006. p. 97-105.

OMOTE, Sadao et al. Atitudes Sociais de educadores em relação à inclusão. In: SIMPÓSIO EM FILOSOFIA E CIÊNCIA, 5., 2003, Marília. Anais eletrônicos... Marília: UNESPMarília-Publicações, 2003. CD ROM.

OMOTE, Sadao et al. Inclusão e a questão das diferenças na educação. Perspectiva: Revista do Centro de Ciências da Educação, São Carlos, v. 24 p. 251-272, 2006. Número Especial.

Mudança de atitudes sociais em relação à inclusão. Paidéia: Cadernos de Psicologia e Educação, Ribeirão Preto, v. 15, n. 32, p. 387-398, 2005.

OMOTE, Sadao. A concepção de deficiência e a formação do profissional em educação especial. In: MARQUEZINE, M. C.; ALMEIDA, M.; TANAKA, E. D. (Org.). Perspectivas multidisciplinares em educação especial II. Londrina: Editora da UEL, 2001. p. 45-52.

A construção de uma escala de atitudes sociais em relação à inclusão: notas preliminares. Revista Brasileira de Educação Especial, Marília, v. 11, n. 1, p. 33-47, 2005.

A formação do professor de Educação Especial na perspectiva da inclusão. In: BARBOSA, Raquel Lazzari Leite (Org.). Formação de educadores: desafios e perspectivas. São Paulo, SP: Editora da UNESP, 2003. p. 153-169.

Estereótipos a respeito de pessoas deficientes. São Paulo, SP: Didática, 1990.

PEREIRA JUNIOR, Antonio Alexandre. Atitudes sociais de professores da rede de ensino municipal de Guarapuava - PR em relação à educação inclusiva. 2009. Dissertação

(Mestrado em Educação) - Faculdade de Filosofia e Ciências, Universidade Estadual Paulista, Marília, 2009. 
PINHEIRO, Eliane Maria Carrit Delgado. Professores do ensino regular e a educação inclusiva de alunos com perda auditiva. 2003. Tese (Doutorado em Educação) - Faculdade de Filosofia e Ciências, Universidade Estadual Paulista, Marília, 2003.

POZO, Juan Ignácio. Aprendizes e mestres: a nova cultura da aprendizagem. Porto Alegre, RS: Artmed, 2002.

RODRIGUES, Aroldo. Psicologia social para principiantes: estudo da interação humana. Petrópolis, RJ: Vozes, 2007. . Psicologia social. 2. ed. Rio de Janeiro, RJ: Vozes, 1973.

RODRIGUES, Aroldo; ASSMAR, Eveline Maria Leal; JABLONSKI, Bernardo. Psicologia Social. 27. ed. rev. e ampl. Petrópolis: Vozes, 2009.

SADE, Rossana Maria S.; CHACON, Miguel Claudio M. Os meandros familiares, escolares e sociais da construção da identidade do deficiente. In: OLIVEIRA, Anna Augusta Sampaio de; OMOTE, Sadao; GIROTO, Claudia Regina Mosca (Org.). Inclusão escolar: as contribuições da educação especial. São Paulo: Cultura Acadêmica; Marília: Fundepe Editora, 2008. p. 93107.

SIEGEL, Sidney. Estatística não-paramétrica para as ciências do comportamento. São Paulo, SP: McGraw-Hill do Brasil, 1981.

SILVA, Esther Giacomini. O perfil docente para a educação inclusiva: uma análise das atitudes, habilidades sociais e o perfil escolar inclusivo. 2008. Tese (Doutorado em Educação) - Faculdade de Filosofia e Ciências, Universidade Estadual Paulista, Marília, 2008.

WANDERLEY, Mariangela Belfiore. Refletindo sobre a noção de exclusão. In: SAWAIA, Bader (Org.). As artimanhas da exclusão: análise psicossocial e ética da desigualdade social. Petrópolis, RJ: Vozes, 2009. p. 16-26.

YURKER, H. E. The effects of contact on attitudes toward disabled persons: some empirical generalizations. In: Springer, 1988. p. $262-274$. 